\title{
Partially coupled spin-up of the MPI-ESM: implementation and first results
}

\author{
M. Thoma ${ }^{1}$, R. Gerdes ${ }^{1}$, R. J. Greatbatch ${ }^{2}$, and H. Ding ${ }^{2}$ \\ ${ }^{1}$ Alfred Wegener Institute Helmholtz Center for Polar and Marine Research, Bussestrasse 24, 27570 Bremerhaven, Germany \\ ${ }^{2}$ GEOMAR Helmholtz Centre for Ocean Research Kiel, Düsternbrooker Weg 20, 24105 Kiel, Germany
}

Correspondence to: M. Thoma (malte.thoma@awi.de)

Received: 4 July 2014 - Published in Geosci. Model Dev. Discuss.: 15 August 2014

Revised: 30 October 2014 - Accepted: 16 December 2014 - Published: 19 January 2015

\begin{abstract}
Large-scale fully coupled Earth system models (ESMs) are usually applied in climate projections like the IPCC (Intergovernmental Panel on Climate Change) reports. In these models internal variability is often within the correct order of magnitude compared with the observed climate, but due to internal variability and arbitrary initial conditions they are not able to reproduce the observed timing of climate events or shifts as for instance observed in the El NiñoSouthern Oscillation (ENSO), the Pacific Decadal Oscillation (PDO), or the Atlantic Meridional Overturning Circulation (AMOC). Additional information about the real climate history is necessary to constrain ESMs; not only to emulate the past climate, but also to introduce a potential forecast skill into these models through a proper initialisation. We attempt to do this by extending the fully coupled climate model Max Planck Institute Earth System Model (MPI-ESM) using a partial coupling technique (Modini-MPI-ESM). This method is implemented by adding reanalysis wind-field anomalies to the MPI-ESM's inherent climatological wind field when computing the surface wind stress that is used to drive the ocean and sea ice model. Using anomalies instead of the full wind field reduces potential model drifts, because of different mean climate states of the unconstrained MPI-ESM and the partially coupled Modini-MPI-ESM, that could arise if total observed wind stress was used. We apply two different reanalysis wind products (National Centers for Environmental Prediction, Climate Forecast System Reanalysis (NCEPcsfr) and ERA-Interim reanalysis (ERAI)) and analyse the skill of Modini-MPI-ESM with respect to several observed oceanic, atmospheric, and sea ice indices. We demonstrate that Modini-MPI-ESM has a significant skill over the time period 1980-2013 in reproducing historical climate fluctuations, indicating the potential of the method for
\end{abstract}

initialising seasonal to decadal forecasts. Additionally, our comparison of the results achieved with the two reanalysis wind products NCEPcsfr and ERAI indicates that in general applying NCEPcsfr results in a better reconstruction of climate variability since 1980 .

\section{Introduction}

Meteorological (atmosphere) forecast models continuously assimilate available observational data to create initial conditions from which the weather is predicted for the next few days. The better the initial conditions are known, the better is the forecast. Therefore, weather forecasts are initial value problems. In contrast, Earth system models (ESMs) used for climate projections documented in the Intergovernmental Panel on Climate Change (IPCC) reports (e.g. Meehl et al., 2007; Stocker et al., 2013) are forced with boundary conditions like solar insolation, volcanic particles injected into the stratosphere, and greenhouse gas concentrations (until the Fourth Assessment Report, AR4) or so-called representative concentration pathways (RCPs) (for the Fifth Assessment Report, AR5). Therefore climate projections are boundary value problems. These fully coupled ESMs are able to reproduce the internal variability of Earth's climate to a certain extent, but fail to simulate the observed timing of events associated with internal climate variability because they are unconstrained by data assimilation. However, for climate projections beyond several decades or even further into the future, the impact of certain emission scenarios exceeds the internal variability, and hence the climate-warming results are reliable (Stocker et al., 2013). 
A classical, dynamic-atmosphere-only weather forecast system cannot be used for monthly, yearly, or even decadal predictions because it lacks the initialisation of slowly varying climate-system components (like the ocean) that are essential for decadal predictability (Murphy et al., 2010). A consequence of the internal dynamic of the atmosphere is that small errors within coupled climate models grow to undesirable and erroneous fluctuations. These could be reduced by an interactive coupled ensemble technique (e.g. Kirtman and Shukla, 2002), but this method does not provide the necessary knowledge of the system state and trajectory at the start of a forecast. Therefore, ESMs can only be used for predictions with proper initialisation.

One method to improve the initialization of a fully coupled model is to assimilate observational data into the ESM. This forces the ESM and, in particular, the components with a longer memory like the ocean close to the observed climate, which is fundamental for any prediction skill. Various techniques and methodologies for the ocean initialisation are possible. They can differ by the variables that are used (sea surface temperature (SST), sea surface salinity (SSS), or surface stress), the initialization procedure's depth range (ocean surface or at depth), and whether anomalies or full fields are used. Servonnat et al. (2014) provides a short introduction and summary of several applied methods. In this study we describe results from a partial coupling technique applied to the Max Planck Institute Earth System Model (MPI-ESM) in which the ocean/sea ice component of the coupled model is driven by time series of observed wind stress computed using observed $10 \mathrm{~m}$ wind anomalies taken from reanalysis (see Sect. 2 for the details). The method is similar to that described in Ding et al. $(2013,2014 b)$ but applied here to the MPI-ESM and using 6-hourly winds instead of monthly mean wind stress anomalies as used by Ding et al. (2013, 2014b). The method has potential for use as an initialisation technique (Ding et al., 2013). However, for a method to be useful as an initialisation technique it must have skill at reconstructing the observed variability of the climate system and it is the purpose of this manuscript to assess the surface wind stress partial coupling technique in this respect (what is hereafter referred to as Modini-MPI-ESM). The method is described in detail in Sect. 2 and in Sect. 3 the model results are compared against observations using some important historical climate indices. Finally, we conclude our study in Sect. 4 (see Appendix Table A1 for a list of the abbreviations used throughout the text).

\section{Model and experimental set-up}

As basis for our model experiments we use the fully coupled atmosphere-land-surface-ocean-sea ice model MPIESM in the very same LR (atmospheric resolution) configuration applied for the Coupled Model Intercomparison Project Phase 5 (CMIP5) experiments. The ocean model (called MPIOM ) has 40 vertical levels and a horizontal resolution of about $12-150 \mathrm{~km}$ on a curvilinear orthogonal grid with poles over Antarctica and Greenland. For the atmosphere model ECHAM6 the horizontal resolution is T63 (about $200 \mathrm{~km}$ ) with 47 vertical levels including the upper stratosphere up to $0.1 \mathrm{hPa}$ (Müller et al., 2012). We modified the ocean-sea ice component (called MPIOM) of this fully coupled MPI-ESM to optionally incorporate external wind forcing data when computing the surface wind stress used to drive the ocean-sea ice component of MPI-ESM, building on approaches adopted by Lu and Zhao (2012) and Ding et al. (2013, 2014b).

In the present study we use two wind-forcing reanalysis products: National Centers for Environmental Prediction, Climate Forecast System Reanalysis (NCEPcsfr) (Saha et al., 2010) and ERA-Interim reanalysis (ERAI) (Dee et al., 2011). Both data products are available on a regular geographic grid with a temporal resolution of $6 \mathrm{~h}$ from 1980 onwards. We interpolate the data within the Max Planck Institute Ocean Model spatially onto the curvilinear orthogonal grid of the ocean model and temporally onto the exact model time step (1.2 $\mathrm{h}$ for the LR-resolution). However, the coupling cycle between the the atmospheric component ECHAM6 and the oceanic component remains $24 \mathrm{~h}$ as in the original CMIP5 configuration.

The wind stresses $\boldsymbol{\tau}$ over sea ice and open ocean are estimated from the observed wind velocities using bulk formulae according to Large and Yeager (2009). These formulae consider the actual modelled sea ice and ocean-surface velocities within MPIOM (Max Planck Institute Ocean Model) and estimate the stress from the relative velocities between reanalysis and the model ocean and sea ice, respectively.

This assimilation procedure allows switching between the unconstrained fully coupled MPI-ESM and the partially coupled Modini-MPI-ESM at any time. If the Modini-mode is switched off, Modini-MPI-ESM calculates the wind stresses according to the dynamics of the fully coupled MPI-ESM. If the Modini mode is active the wind stress is overwritten by that estimated from the reanalysis products. In this study we limit our analysis to partially coupled model experiments, which are restarted in 1980 from fully coupled MPI-ESMCMIP5 experiments and run until 2013. The applied atmospheric forcing is identical to the historical-CMIP5 scenarios until 2005, and is extended by the RCP4.5-emission scenarios thereafter. It should be noted that SST is computed using the coupled model physics and is not directly constrained in Modini-MPI-ESM. Likewise, ECHAM6 computes its own wind field and only knows about the observed time series of events through the SST that is given to it by the ocean model and the influence of the specified radiative forcing.

It is possible to apply a full-field forcing, where the wind stress is directly calculated from the reanalysis wind field $\boldsymbol{v}^{\text {re }}$ :

$\boldsymbol{v}^{\mathrm{ff}}(t)=\boldsymbol{v}^{\mathrm{re}}(t)$. 
However, we rather consider an anomaly forcing, where only deviations from the long-term model mean (the model's inherent climatology $\boldsymbol{v}_{\text {clim }}^{\text {CMIP5 }}$ ) are considered:

$\boldsymbol{v}^{\mathrm{af}}(t)=\boldsymbol{v}^{\mathrm{re}}(t)-\boldsymbol{v}_{\mathrm{clim}}^{\mathrm{re}}+\boldsymbol{v}_{\mathrm{clim}}^{\mathrm{CMIP} 5}$,

where the MPI-ESM climatology $\boldsymbol{v}_{\text {clim }}^{\text {CMIP5 }}$ is estimated from the three original ensemble members of the MPI-ESM CMIP5 experiments (Giorgetta et al., 2013). This anomaly forcing reduces model shocks and drifts compared to the alternative full-field forcing when switching back and forth between the fully coupled MPI-ESM and the partially coupled Modini-MPI-ESM mode.

We generated 15 ensemble members for Modini-NCEP and 10 for Modini-ERAI. By analysing the ensemble mean we filter out large parts of the internal model variability and enhance the visibility of the model's response to the external wind and GHG (greenhouse gas) forcing. The individual ensemble members are generated by lagged initialisations from one of the three original CMIP5 experiments.

\section{Model experiment evaluation}

To estimate the ability of the partially coupled Modini-MPIESM to track the time evolution of the observed climate system compared to the fully coupled Earth system model MPIESM, we consider several spatial and/or time dependent climate indices for ocean, atmosphere, and sea ice in both hemispheres. For each of these control variables, the results of the fully coupled MPI-ESM-CMIP5 experiment are compared with the equivalent Modini-MPI-ESM outcomes. For comparisons we use not only the three original CMIP5 ensemble members, but also seven additional realisations, which were later performed at the Max Planck Institute (MPI).

\subsection{Oceanic indices}

\subsubsection{Global SST distribution}

We use the Met Office Hadley Centre's sea ice and sea surface temperature data set (HADIsst) (Rayner et al., 2003) to estimate the skill of the Modini-MPI-ESM model. The climatological differences between the observed and the ensemble mean CMIP5-modelled SSTs are shown in Fig. 1a. The largest differences of up to about $5 \mathrm{~K}$ are found in the North Atlantic, the upwelling regions off the west coasts of America and Africa and in the Southern Ocean. These differences are known biases of the MPI-ESM that are also common to most other Earth system climate models (Jungclaus et al., 2013). The wind forcing in the Modini-MPI-ESM (Fig. 1aN, $\mathrm{aE})$ reduces the temperature differences slightly in the Southern Ocean and in the northwestern Pacific (compared to the reference $1 \mathrm{aC}$ ), but otherwise no improvement is achieved. In the Atlantic Ocean, the differences even increase slightly. The global mean SST is about $2.8 \%(3.6,3.7 \%)$ lower in the CMIP5 (Modini-NCEP, Modini-ERAI) experiment, compared with HADIsst.

This slight offset between the MPI-ESM and Modini-MPIESM is a result of several factors: first, compared to our 6hourly wind forcing, the daily-averaged wind fields applied in MPI-ESM smooth out storm track peak winds and inertial oscillations are more efficiently generated (e.g. Weisse et al., 1994; Jochum et al., 2012). Consequently, the 6-hourly wind forced Modini-MPI-ESM has more surface mixing and potentially cooler (global mean) SST. Second, we estimate the wind stress according to the bulk formulae of Large and Yeager (2009), taking into account the modelled surface velocities of ocean and sea ice. Finally, nonlinearities in coupled climate models, e.g. in the ice sheet model or the bulk formulae, might intensify deviations from a mean state, leading to the slightly different climate states of MPI-ESM and ModiniMPI-ESM.

Although the climatological temperature distribution does not improve globally by the partial coupling, the correlation between the modelled (CMIP5, Modini-NCEP, ModiniERAI) and the observed (reference) annual mean SSTs show a clear global improvement compared to the CMIP5experiments (Fig. 1b) despite the fact no direct constraint is placed on the model SST. In wide areas of the Pacific and Indian oceans the correlation exceeds 0.5 (Fig. $1 \mathrm{bN}$ ) and are highly significant ${ }^{1}$ (see Fig. A1a in the Appendix). For monthly mean values high (and significant) correlations are confined to the equatorial Pacific as shown in the Appendix Fig. A1b, c.

In general, the pattern associated with highest correlation in the Modini cases is similar to what one would expect based on the teleconnection pattern from the eastern/central tropical Pacific (compare, for example, with Fig. 3 in Kirtman and Shukla, 2002), indicating that it is the success of the Modini technique in the tropical Pacific that determines much of the skill in other parts of the globe. This is consistent with Ding et al. (2013, 2014a, b).

\footnotetext{
${ }^{1}$ The statistical significance $p$ within this article has been calculated with a Pearson's test using R: cor. text $(x, y)$. Based on a $95 \%$ confidence level, we define them as follows,

\begin{tabular}{ll}
$p$ & significance \\
\hline$\leq 0.001$ & high \\
$\leq 0.01$ & strong \\
$\leq 0.05$ & weak \\
$>0.05$ & none
\end{tabular}

against the null hypothesis. The existence of a potential serial correlation (autocorrelation) is tested by estimating the correlation of the first derivative of the data $R$ : cor.text(diff $(x), \operatorname{diff}(y))$. This checks whether the change in one variable is correlated or a linear function of the change in another.
} 

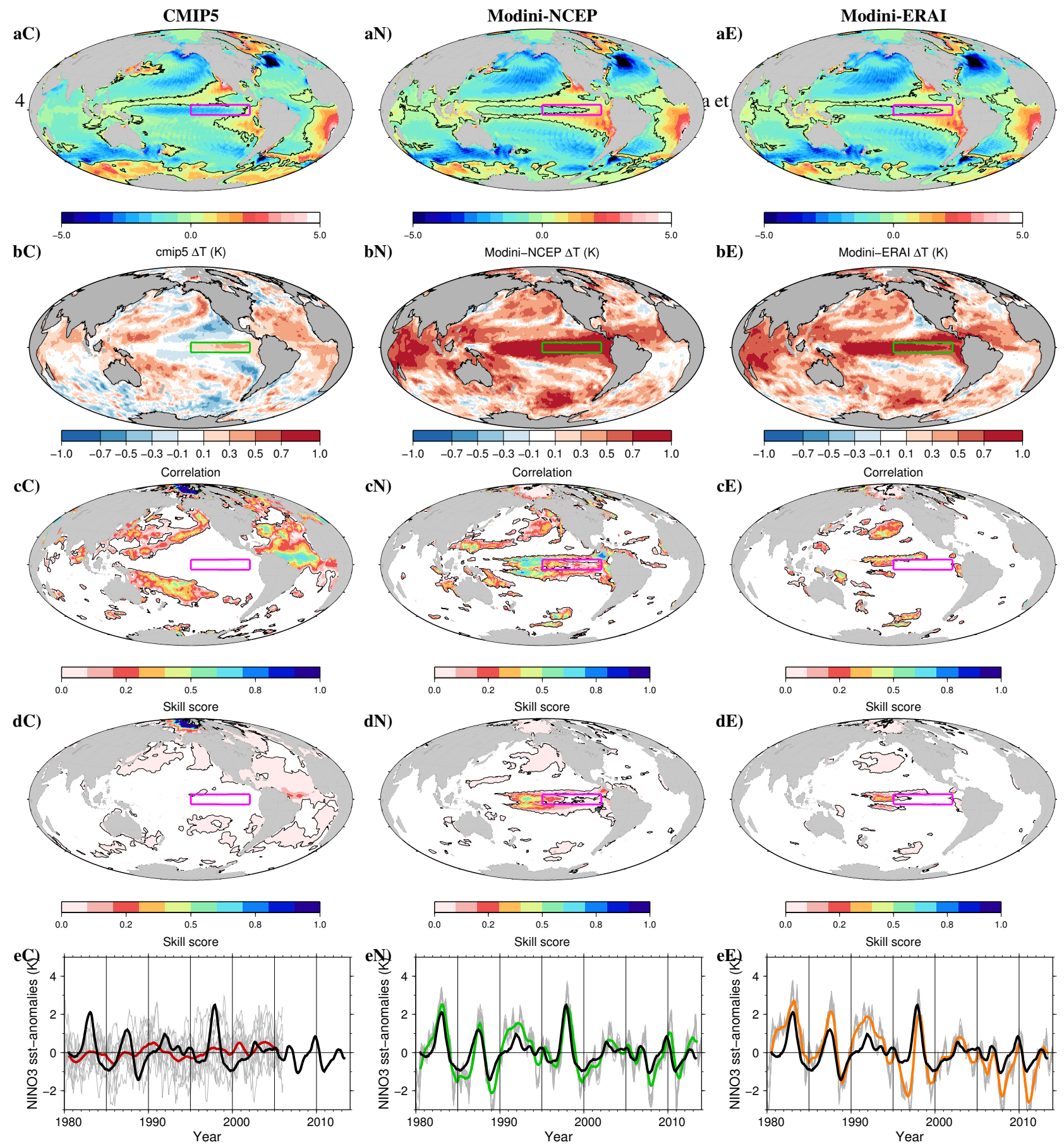

Figure 1. Model results with respect to SSTs for ensemble means.

Left: MPI-ESM-CMIP5 (10 ensemble members), centre: Modini-NCEP (15), right: Modini-ERAI (10).

(a) Mean difference between model and reference SST.

(b) Correlation between the model and the reference SST using detrended annual means for the periods from 1980 (CMIP5) and 1981 onwards (Modini-NCEP, Modini-ERAI), respectively. The boxes indicate the Niño3-region between $5^{\circ} \mathrm{N}-5^{\circ} \mathrm{S}$ and $170^{\circ}-120^{\circ} \mathrm{W}$. The corresponding $p$ values and correlations for monthly means are shown in the Appendix, Fig. A1.

(c) Skill score using (not-detrended) yearly means referenced to HADIsst according to Eq. (3) for the periods from 1980 (CMIP5) and 1982 onwards (Modini-NCEP, Modini-ERAI), respectively.

(d) Like (c) but for monthly means.

(e) Comparison between observed (black, HADIsst) and 12-monthly-running mean of the Niño3 index (averaged sea surface temperature anomalies) for CMIP5 (red), Modini-NCEP (green), and Modini-ERAI (orange). Thin lines indicate individual ensemble members, thick coloured lines the ensemble means. El Niño events are characterised by strong positive temperature anomalies. 
We define a skill score $E$ of a model-ensemble-mean anomaly variable $\widetilde{m}$, with respect to the corresponding reference anomaly $\tilde{r}$ as

$E=1-\frac{\sigma^{2}(\tilde{m}-\widetilde{r})}{\sigma^{2}(\widetilde{r})}$

with the variances $\sigma^{2}(\widetilde{m}-\widetilde{r})=\frac{1}{1-T} \sum_{t=1}^{T}(\widetilde{m}-\widetilde{r})^{2}$ and $\sigma^{2}(\widetilde{r})=$ $\frac{1}{1-T} \sum_{t=1}^{T}(\widetilde{r})^{2}$. Estimating this skill for the yearly and monthly mean SSTs (Fig. 1c, d) shows a significant improvement in the equatorial Pacific for the Modini-NCEP experiment compared to the reference CMIP5 experiment. As for the correlation, the improvement for Modini-NCEP is larger than for Modini-ERAI.

\subsubsection{EI Niño-Southern Oscillation (ENSO)}

The ENSO describes fluctuations around the mean state of the tropical Pacific, which are connected to droughts, floods, and crop yields in several areas (mostly) around the $\mathrm{Pa}$ cific (Philander, 1990). One common way to measure ENSO is the Niño3 index, which is defined as the mean SSTanomaly within the area between $90^{\circ}-150^{\circ} \mathrm{W}$ and $5^{\circ} \mathrm{S}-$ $5^{\circ} \mathrm{N}$ (e.g. Deser and Wallace, 1990; Trenberth, 1997). An El Niño event is characterised by a strong positive temperature anomaly in the equatorial Pacific. Very pronounced events were observed during the boreal winters 1982/83 and 1997/98 (indicated by the black lines in Fig. 1e). The individual ensemble members of the fully coupled CMIP5 experiment, have slightly enhanced amplitudes, but capture roughly the timescales of the observed Niño3 index, indicating the model's internal variability (Fig. 1eC). However, the model spread is large and the observed phase and the amplitude cannot be reproduced without additional information. Consequently the ensemble mean does not contain any information about the ENSO anymore, indicated by the nearly flat thick red line in Fig. 1eC.

Applying the partially coupled Modini wind forcing, this changes significantly: the phase of the Niño3 index is well reproduced in the Modini-NCEP and Modini-ERAI experiments and the model spread is strongly reduced. Additionally, Modini-NCEP (and to a lesser extend also ModiniERAI) is also able to reproduce the amplitude of the Niño3 index very well during the whole time period of the experiment, and the correlation coefficients reach $0.76(0.72)$ for the monthly means from 1982 onwards. Even taking serial correlation into account, the significance is high.

\subsubsection{Pacific Decadal Oscillation (PDO)}

As a third way to assess skill with SST, we turn to the PDO. The PDO is defined as the first empirical orthogonal function (EOF) of (detrended) SST-anomalies north of $20^{\circ} \mathrm{N}$ in the Pacific (Mantua et al., 1997). In general, EOFs consists of a spatial pattern and a corresponding time series (the socalled principal component (PC)). In the case of the PDO, the time series corresponding to the leading EOF is defined as the PDO index. A positive PDO phase is associated with a deepened Aleutian low and therefore has impacts on air temperatures and precipitation in North America. The fishery is also affected as zoo- and phytoplankton are related to changes in the ocean's mixed layer depth. In general, the PDO has two preferred timescales of variability, one of 20-30 years and one of 50-70 years (Vuille and Garreaud, 2012). Therefore the significance of the PDO within the about 30 model years analysed within this study might be limited. We compute the PDO index not from the spatial pattern (the leading EOF) of the modelled SSTs, but from the spatial pattern of the observed HADIsst (Fig. 2a), which reaches back to the 19th century. The resulting PDO indices are shown in Fig. 2b. In contrast to the Niño3 index, the model spreads are quiet large for the Modini-NCEP and Modini-ERAI experiments. As a consequence of different climate states in MPI-ESM and Modini-MPI-ESM (see Sect. 3.1.1), there is also a spinup signal during the first 2 years until about 1982 in both Modini experiments. While there is no significant correlation between the CMIP5-experiments and the observed PDO, Modini-NCEP (as well as Modini-ERAI) experiments show a clear improvement in phase and amplitude, resulting in an increased correlation coefficient of 0.62 from 1982 onwards for both experiments between the model ensemble monthly means and the observed time series. The correlation is highly significant and serial correlation does not play a role for the estimated PDO index in our experiments.

\subsubsection{Atlantic Multidecadal Variability (AMV)}

As a final SST-skill test we analyse the AMV (sometimes also referred to as Atlantic Multidecadal Oscillation or AMO). It is defined as the detrended SST mean between the Equator and $70^{\circ} \mathrm{N}$ in the Atlantic sector between $80^{\circ} \mathrm{W}$ and the Greenwich meridian after removing the seasonal cycle (e.g. Enfield et al., 2001). The comparisons between the observed (Kaplan et al., 1998) and modelled AMVs are shown in Fig. 3.

The modelled period is too short to represent the typical 80-year timescale of the AMV, but teleconnections with ENSO (varying on an interannual timescale) might lead to some skill (Enfield et al., 2001). A second caveat is the significant SST offset in the North Atlantic (Fig. 1a), although this might not prevent model skill with the SST variability (rather than the absolute values). 


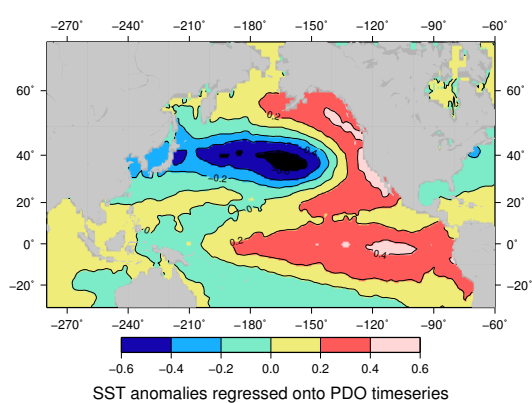

bC)

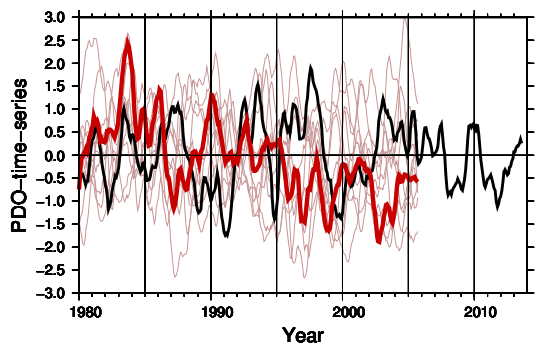

bN)

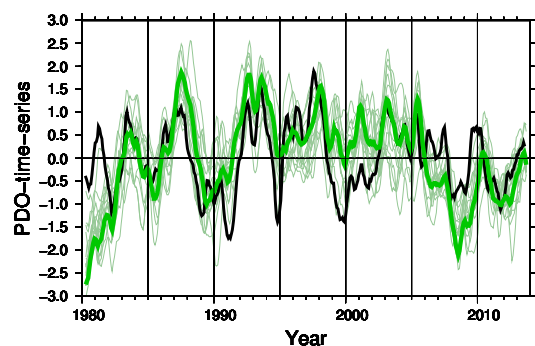

bE)

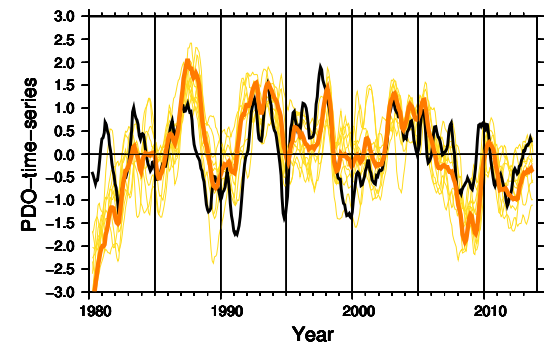

Figure 2. (a) Spatial pattern of the observed HADIsst regressed onto the PDO index. (b) PDO indices (6-month running means) for the observed HADIsst (black) and the CMIP5 (red), Modini-NCEP (green), and Modini-ERAI (orange) experiments. Thin lines indicate ensemble members, thick lines show the PDO indices computed from the ensemble SST means.

CMIP5

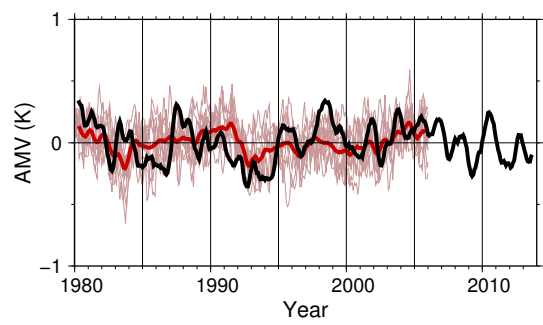

Modini-NCEP

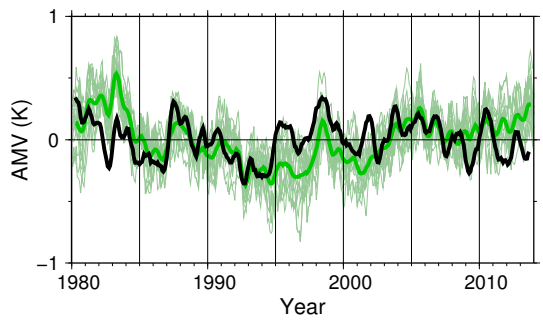

Modini-ERAI

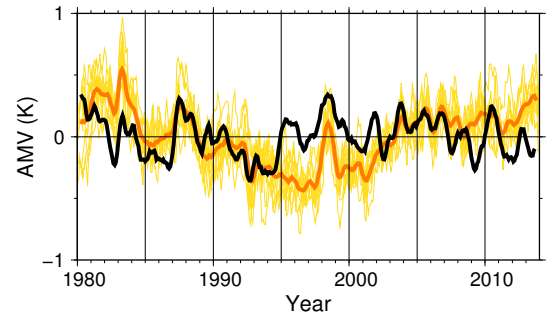

Figure 3. Comparison between observed (black) and modelled detrended 6-month running mean AMV index with removed seasonal cycle for CMIP5 (red), Modini-NCEP (green), and Modini-ERAI (orange). Thin lines indicate individual ensemble members, thick lines ensemble means.

Indeed, we find a highly significant correlation of 0.35 for the 6-month running mean Modini-NCEP experiment from 1982 onwards (Fig. 3). For Modini-ERAI the correlation is somewhat lower (0.23). In both Modini experiments, serial correlation is not important. But there is also a highly (serially correlated) significant correlation (0.36) in the ensemble mean of the CMIP5 experiments. This correlation cannot be caused by anthropogenic forcing of the CMIP5 experiments, because we estimate the correlation coefficient from detrended time series. However, the prominent decrease from 1991 onwards indicate, that volcanic eruptions have an significant impact on the AMV (compare Sect. 3.2.2). A proper representation of other atmospheric forcings like stratospheric aerosols and ozone, which are also included in CMIP5 experiments, might also lead to the comparable correlation coefficients between MPI-ESM and Modini-MPIESM.

\subsubsection{Atlantic meridional overturning circulation}

The Atlantic Meridional Overturning Circulation (AMOC) is the stream function of the zonally integrated transport and closely related to the global thermohaline circulation. A mooring array known as the RAPID-MOCHA array, has been deployed at $26^{\circ} \mathrm{N}$ between the Bahamas and the Canary Islands. This array provides continuous measurements of the strength and variability of this circulation since 2004 (Cunningham et al., 2007; Send et al., 2011; Smeed et al., 2014). The time series of this measured AMOC strength is available until October 2013. Figure 4 shows that the difference in the vertically integrated stream function in the Atlantic between the CMIP5 and the Modini experiments is rather small. However, the time series of Modini-NCEP and Modini-ERAI show, despite the short time period, a remarkable agreement in phase and amplitude with the RAPID monitoring. In par- 

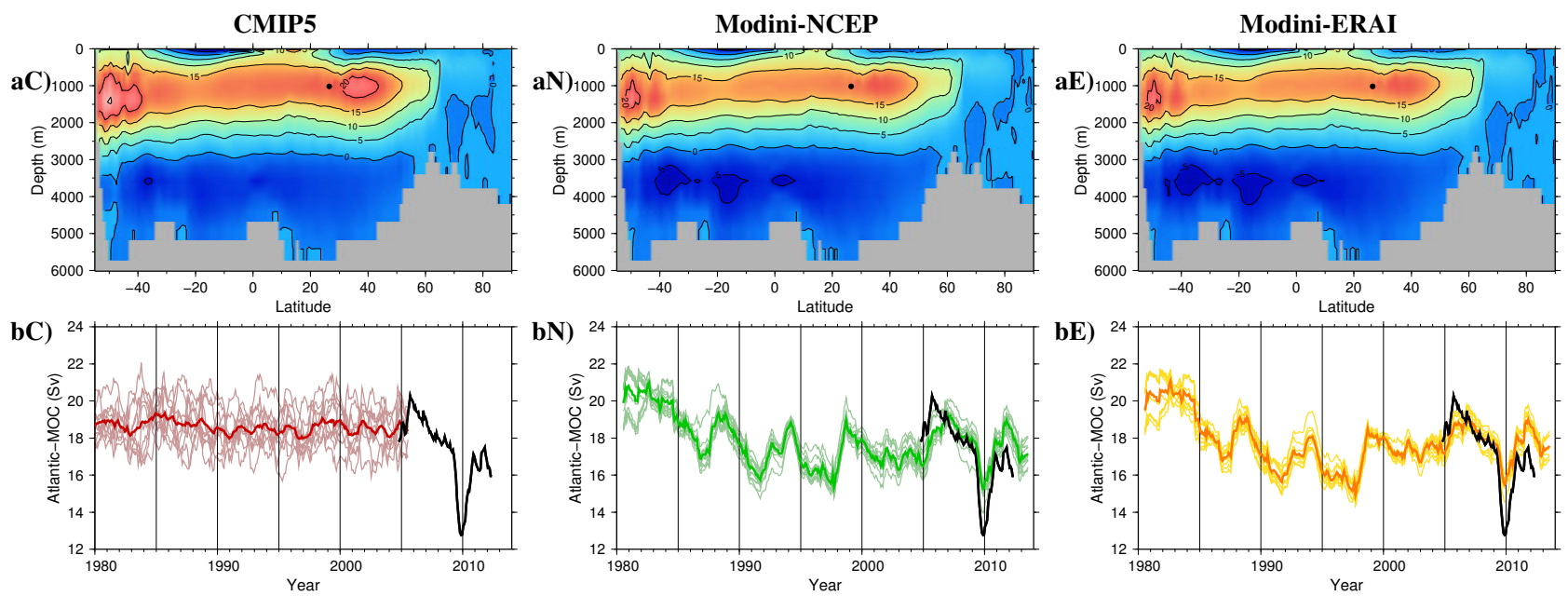

Figure 4. Comparison between observed (black, RAPID) and 12-monthly running mean of monthly mean modelled AMOC for CMIP5 and Modini-MPI-ESM at $26^{\circ} \mathrm{N}$. The black dot in the upper panels indicates the position of the RAPID array. Lighter colours belong to individual ensemble members.

ticular, the significant weakening of the AMOC in 2009/2010 is quite well captured with Modini-ESM. The highly significant correlation coefficients for the AMOC are 0.89 (ModiniNCEP) and 0.94 (Modini-ERAI) and have an insignificant serial correlation.

These results imply that a large part of the interannual variability in RAPID can be explained by wind forcing alone. This is because MODINI-ESM knows about the observed time series of interannual variability only through the wind stress anomalies used to drive the ocean component. However according to Fan and Schneider (2011), this wind-driven skill arises primarily from weather noise and is therefore not predictable.

In contrast, the delayed AMOC response on decadal or interdecadal timescales is related to the surface heat flux (Eden and Willebrand, 2001; Eden and Jung, 2001) and would therefore most likely not be captured by the wind-only forced Modini-MPI-ESM.

\subsection{Atmospheric indices}

\subsubsection{Surface air temperature (SAT)}

The atmosphere is totally unconstrained in the Modini-MPIESM. The external wind forcing interacts with the atmosphere only indirectly via the SST response to the wind stress. However, in large areas of the Pacific and Indian Oceans a significant correlation between the annual means of the modelled Modini-NCEP (Modini-ERAI) $2 \mathrm{~m}$ temperature and the ERAI reanalysis (Fig. $5 \mathrm{aN}, \mathrm{aE}, \mathrm{bN}, \mathrm{bE}$ ) exists. The global average of these correlations is significantly larger ( 0.40 and 0.31 , respectively) than for the fully coupled CMIP5 experiment (Fig. 5aC, 0.15). For the Modini-NCEP experiment not only do large parts of the Pacific and the Arctic oceans show correlations above 0.5 but, additionally, the
Table 1. Definition of regions to calculate the mean near-surface air temperature in Fig. 6 and number of months applied to calculate the running mean values for Fig. 6 and Table 2.

\begin{tabular}{lllr}
\hline Region & Longitude & Latitude & Months \\
\hline Global & $0-360^{\circ} \mathrm{E}$ & $80^{\circ} \mathrm{S}-80^{\circ} \mathrm{N}$ & 3 \\
Europe & $10^{\circ} \mathrm{W}-42^{\circ} \mathrm{E}$ & $36-62^{\circ} \mathrm{N}$ & 12 \\
Africa & $15^{\circ} \mathrm{W}-52^{\circ} \mathrm{E}$ & $36^{\circ} \mathrm{S}-35^{\circ} \mathrm{N}$ & 3 \\
N America & $136-75^{\circ} \mathrm{W}$ & $31-63^{\circ} \mathrm{N}$ & 12 \\
S America & $82-36^{\circ} \mathrm{W}$ & $51^{\circ} \mathrm{S}-11^{\circ} \mathrm{N}$ & 3 \\
Asia & $37-145^{\circ} \mathrm{E}$ & $37-70^{\circ} \mathrm{N}$ & 12 \\
Australia & $113-155^{\circ} \mathrm{E}$ & $38-11^{\circ} \mathrm{S}$ & 12 \\
\hline
\end{tabular}

$2 \mathrm{~m}$ temperatures over the continents also have a significantly positive correlation with the reanalysis data. Note that the correlations between the model results and the NCEPcsfr reanalysis data set (instead of the ERA-Interim data set) are only slightly smaller ( 0.37 and 0.28 , not shown). This indicates that our Modini results are quite robust, with respect to different reanalysis products.

\subsubsection{Mean global and regional SAT temperatures}

The global mean temperature rise is one of the most cited values, with respect to climate change. Here, we compare the skill of the original CMIP5 experiment and the Modini-MPIESM to reproduce observed mean temperatures, represented by the ERAI reanalysis. We compare the global mean as well as temperatures for each continent separately; the individual regions are defined in Table 1.

In general, the observed global temperatures increase during the period from 1980 to 2013 . However, temporary cooling effects of the El Chichón and Mt Pinatubo eruptions 

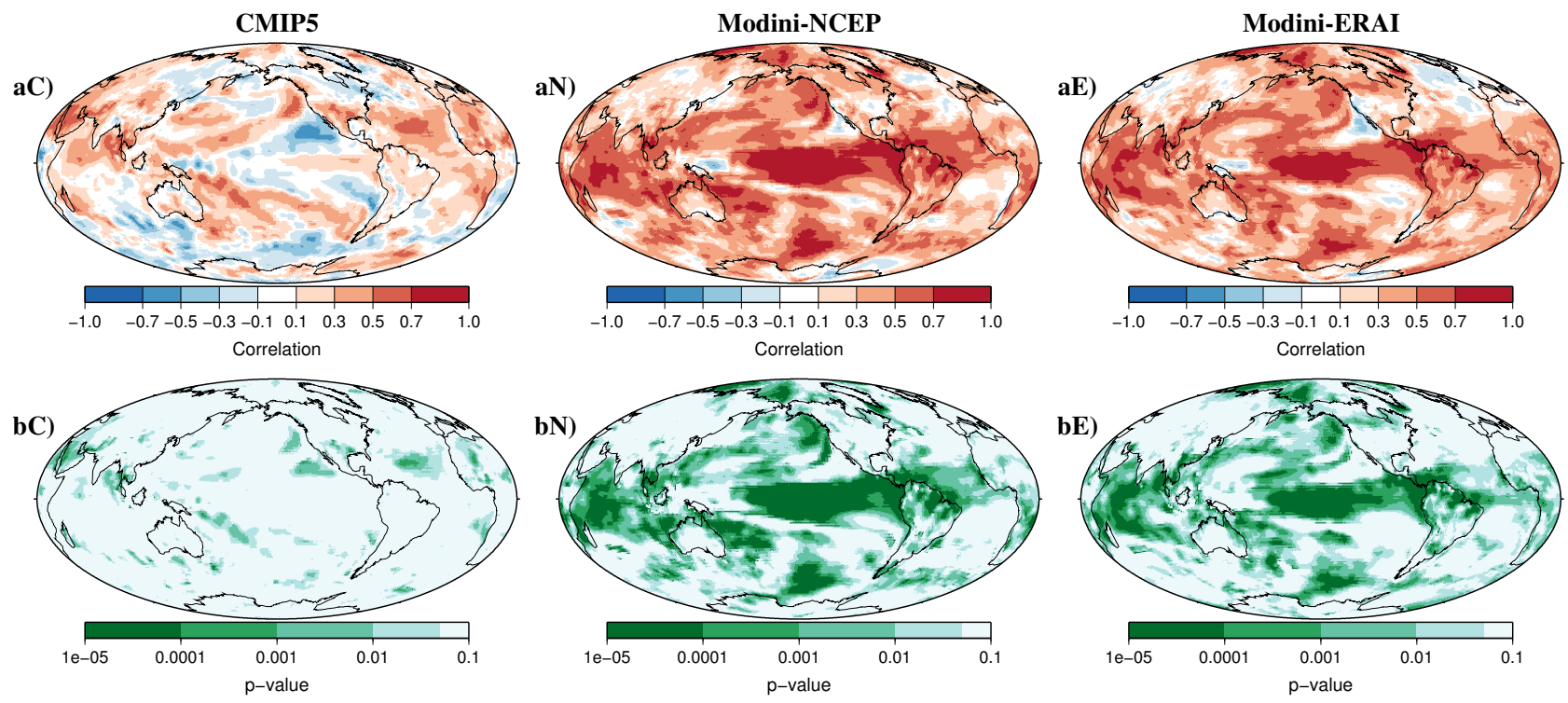

Figure 5. Correlation (top) and corresponding $p$ values (bottom) between modelled and observed (ERA-Interim) detrended yearly mean atmospheric near-surface temperatures for the periods from 1980 and 1985 onwards for the CMIP5- and Modini-experiments, respectively.

in March 1982 and June 1991, respectively, as well as a natural climate variability hiatus from about 2000 onwards (e.g. Kosaka and Xie, 2013), superimpose the overall upward trend during the modelled period. In the ensemble mean of the CMIP5 experiments (Fig. 6, left) the temperature drop of about $0.5 \mathrm{~K}$ after the enormous amount of volcanic particles injected into the stratosphere from Mt Pinatubo (e.g. McCormick et al., 1995) is reproduced well. The smaller cooling impact of the El Chichón eruption is also visible in the global mean and on most continents. However, the observed global interannual fluctuations, or on individual continents, are not reproduced in the CMIP5 experiments. With respect to this, Modini-MPI-ESM has a significant skill. For Australia, South America, Africa, and globally, the mean temperature from Modini-NCEP and Modini-ERAI does not only feature the volcanically induced temporary coolings, but also 40-62\% percent of the observed interannual fluctuations are well reproduced from 1982 onwards, indicated by significant correlation coefficients (Table 2). For Europe, NorthAmerica and Asia, however, the ensemble spread is quite larger and therefore the weak correlations are insignificant for the Northern Hemisphere continents. Note that the lower mean global SST in Modini-MPI-ESM, compared to MPIESM (Sect. 3.1.1), results in an artificial transition phase on all continents during the first (approximately) 5 model years. After 1985 the general (linear) trends (indicated by dotted lines in Fig. 6) are very well reproduced with Modini-MPIESM.
Table 2. Correlation coefficients (CC) and significance for a $95 \%$ confidence level for detrended and seasonal-cycle removed $x$ running mean monthly temperatures from 1982 onwards. The value $x$ is given in Table 1. Serial correlation is taken into account for the significance. Insignificant correlations are parenthesised.

\begin{tabular}{llllll}
\hline \multirow{2}{*}{ Region } & \multicolumn{2}{c}{ Modini-NCEP } & & \multicolumn{2}{c}{ Modini-ERAI } \\
\cline { 2 - 3 } \cline { 5 - 6 } & CC & significance & & CC & significance \\
\hline Global & 0.41 & high & & 0.43 & high \\
Europe & $(0.11)$ & none & & $(0.04)$ & none \\
Africa & 0.40 & high & & 0.46 & strong \\
N America & $(0.11)$ & none & & $(0.29)$ & none \\
S America & 0.63 & high & & 0.60 & high \\
Asia & 0.18 & high & & $(0.15)$ & none \\
Australia & 0.54 & high & & 0.43 & high \\
\hline
\end{tabular}

\subsubsection{Southern Annular Mode (SAM)}

The SAM is a low-frequency mode of atmospheric variability of the Southern Hemisphere. It is characterised by anomalies in pressure over Antarctica and averaged over the latitude band $40-50^{\circ} \mathrm{S}$ that vary out of the phase with each other on monthly timescales and longer. The SAM is also sometimes referred to as the Antarctic Oscillation (AAO). It has a significant impact on the climate in Antarctica and other highlatitude Southern Hemisphere land masses. In its positive phase it is associated with strengthened westerlies, resulting in an unusual cold central Antarctica but also in higher temperatures at the Antarctic Peninsula and is therefore possibly related to the thinning and breakup of the Larsen A and 


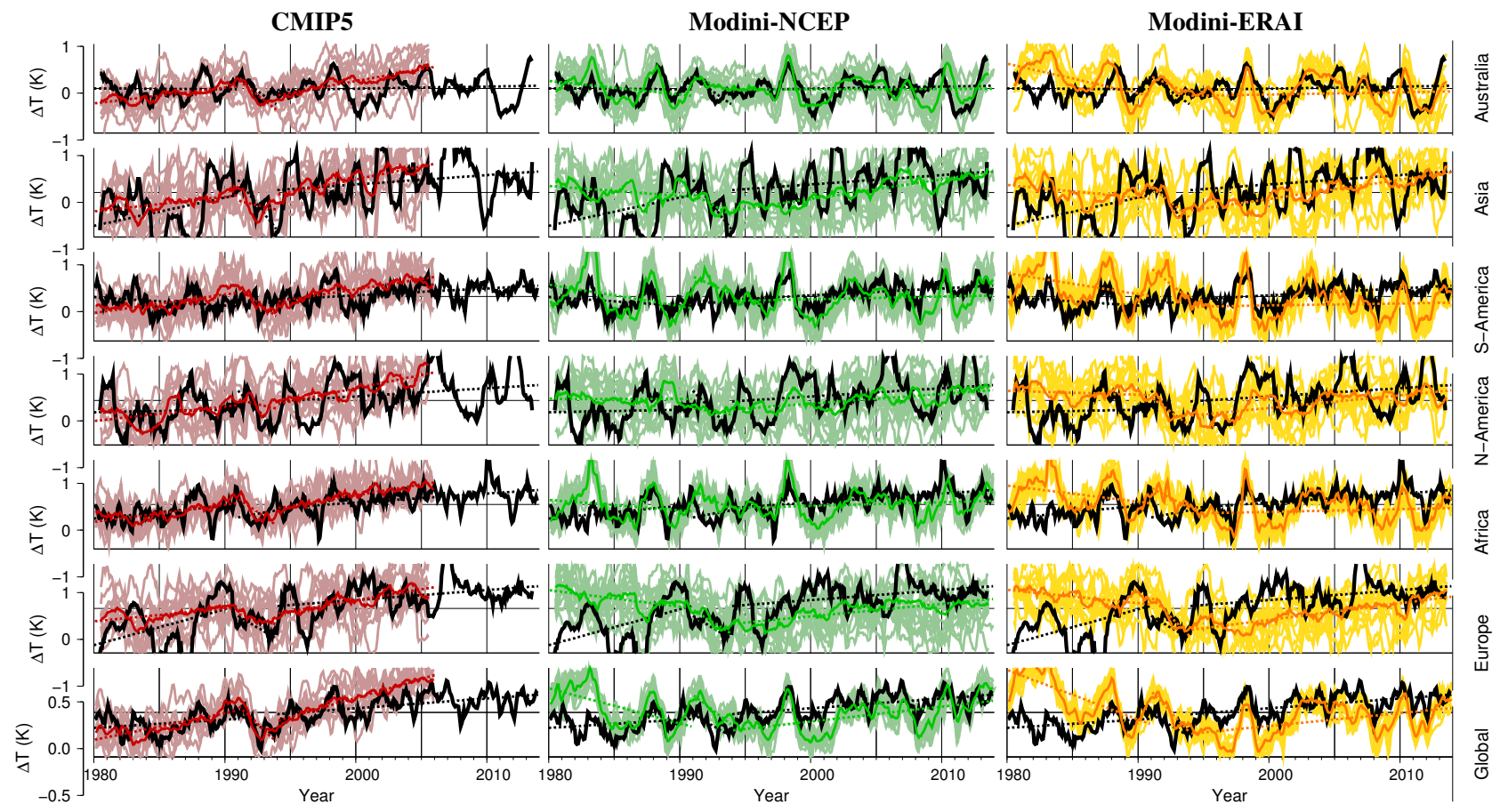

Figure 6. Average near-surface air temperature for different regions with removed seasonal cycle. Thin coloured lines indicate individual ensemble members, thick coloured lines the ensemble means, dotted lines are linear trends for three time periods (until end of 1990, between early 1991 and end of 1993, and from early 1994 onwards). Black lines indicates the corresponding references according to the ERA-Interim reanalysis. See Table 1 for definition of regions and applied running-mean smoothing.

Larsen B ice shelves (e.g. Rott et al., 1996; Shepherd et al., 2003).

Different SAM definitions exist: it is either calculated from monthly mean anomalies of the normalised difference in the zonal mean sea level pressure (SLP) between 40 and $65^{\circ} \mathrm{S}$ (Gong and Wang, 1999; Marshall, 2003) or is defined as the leading principal component (PC) of the monthly mean anomalies of the $850 \mathrm{hPa}$ geopotential height anomalies (GPHAs) south of $20^{\circ} \mathrm{S}$ (Thompson and Wallace, 2000). As before (see Sect. 3.1.3), we do not project the modelled GPHA onto the modelled leading EOF, but onto the spatial pattern of the reanalysis data.

The results for 12-month running means using both SAMdefinitions are shown in Fig. 7. The difference between both definitions is marginal. As expected, the CMIP5 experiments show no significant correlation at all. For the Modini-NCEP (Modini-ERAI) experiments the correlations of the 12-month running-mean ensemble means show a correlation of 0.5 (0.48) and $0.44(0.38)$ for the GPHA and SLP definitions, respectively. These correlations are highly significant, taking serial correlation into account, and indicate that ModiniMPI-ESM has a skill for the SAM climate indicator. This is consistent with Mo (2000) and Ding et al. (2012), who found a relationship between the SAM and the ENSO-variability and $\mathrm{Lu}$ and Zhao (2012), who showed that there is a positive wind-stress feedback on the SAM. Readers are referred to Ding et al. (2014a) for further discussion of tropical influences on the SAM which, in turn, since they are of tropical origin, have the potential to be captured by Modini.

\subsubsection{North Atlantic Oscillation (NAO)}

The NAO is the most important climate indicator in the Northern Hemisphere. It is often defined in terms of the fluctuations in the difference of SLP between the Icelandic low and the Azores high. It measures the strength and direction of westerly winds and storm tracks across the North Atlantic towards Europe. Here we apply two definitions of the NAO index by Hurrell et al. (2003) and Li and Wang (2003). First, the classical Hurrell index which is defined as the PC of the leading EOF of the SLP anomalies over the Atlantic sector across $20-80^{\circ} \mathrm{N}$ and $90^{\circ} \mathrm{W}-40^{\circ} \mathrm{E}$. The latter estimates the NAO index as the normalised difference in SLP between 20 and $90^{\circ} \mathrm{N}$, averaged over the whole North Atlantic sector from $80^{\circ} \mathrm{W}$ to $30^{\circ} \mathrm{E}$, and is (according to the authors) a more faithful representation of the spatio-temporal variability associated with the NAO on all timescales. As for the PDO in Sect. 3.1.3, we compute the NAO index not from the spatial pattern (the leading EOF) of the modelled GPHAs, but from the spatial pattern of the corresponding reference data set (ERAI). We limit our analysis to the boreal winter (DJF) NAO (for monthly mean SLPs), which has the strongest tem- 

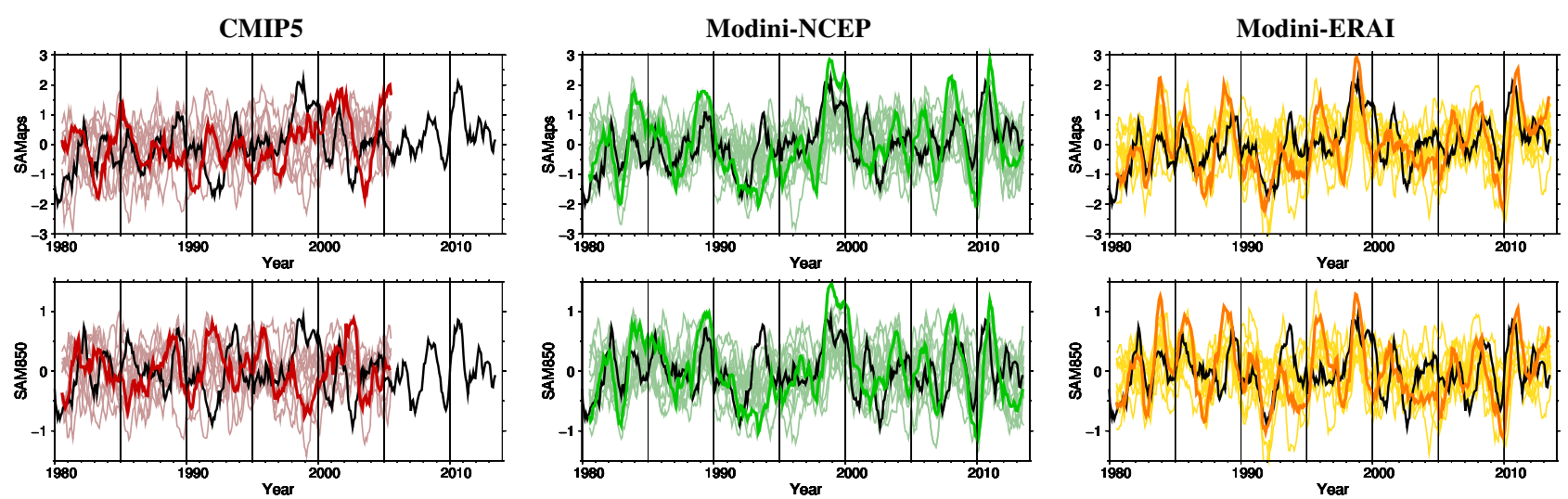

Figure 7. Twelve-month running mean of the SAM calculated for the CMIP5 and Modini experiments from the monthly mean sea surface pressure difference (top) and the $850 \mathrm{hPa}$ geopotential height (bottom). Thin coloured lines indicate individual ensemble members, thick coloured lines the SAM calculated from the ensemble mean sea surface pressure and geopotential height, respectively. Black lines indicate the corresponding references according to the ERA-Interim reanalysis.

Table 3. NAO correlation coefficient (CC) and significance for a $95 \%$ confidence level according to the definitions of Hurrell et al. (2003) (H) and Li and Wang (2003) (L) for Modini-NCEP and Modini-ERAI from 1982 and 1987 onwards. Serial correlation does not play a role.

\begin{tabular}{llcclccc}
\hline & & \multicolumn{2}{c}{ Modini-NCEP } & & \multicolumn{2}{c}{ Modini-ERAI } \\
\cline { 3 - 4 } \cline { 7 - 8 } & & CC & Sign. & & CC & Sign. \\
\hline H & $1982-$ & 0.12 & weak & & - & none \\
L & $1982-$ & 0.21 & high & & 0.11 & weak \\
H & $1987-$ & 0.39 & high & & 0.19 & high \\
L & $1987-$ & 0.48 & high & & 0.30 & high \\
\hline
\end{tabular}

poral variance (e.g. Hurrell et al., 2003). Both indices are shown in Fig. 8.

As expected, there is no correlation between the observed and modelled NAO index for the CMIP5 experiments (Fig. 8). But both Modini-MPI-ESM experiments show a significant correlation, at least from 1987 onwards (Fig. 8, Table 3). Serial correlation does not play a role for the winter NAO.

In general, the NAO index according to $\mathrm{Li}$ and Wang (2003) results in slightly higher correlation coefficients and the NCEP-forcing reproduces the observed NAO index much better than the ERAI-forcing. We conclude, that ModiniMPI-ESM has some NAO-skill. One possible source of this skill is a tropical forcing, which can influence the NAO (Greatbatch et al., 2012; Vuille and Garreaud, 2012; Hurrell et al., 2003).

\subsection{Sea ice extent and volume}

The sea ice model within MPIOM consists of a dynamic part, based on a viscous-plastic rheology (Hibler, 1979), and a thermodynamic part, based on a zero-layer model (Semtner, 1976, 1984). Although the MPIOM applies only a simplified single-ice-class approximation, the results of the fully coupled MPI-ESM agree in general quite well with the observed Arctic sea ice cover. According to Notz et al. (2013), who compared the MPI-ESM output with the National Snow and Ice Data Center-Climate Data Record (NSIDC-CDR) data set, the model performs much better than its predecessor ECHAM5/MPIOM. It even produces the most realistic sea ice concentrations among all CMIP5 models (RiemannCampe and Gerdes, 2013).

The main spatial differences between the fully coupled MPI-ESM and the Modini-ESM-MPI occur in the Sea of Okhotsk in the Pacific sector, where MPI-ESM has much less and Modini-ESM-MPI too much sea ice in terms of concentration compared with OSISAF (Ocean and Sea Ice Satellite Application Facility; not shown here).

Here we concentrate on the impact of the partially coupled forcing on the Arctic sea ice extent (SIE) and sea ice volume (SIV) time dependence. The seasonal cycles of both indicators have a slight offset with respect to the reanalysis data (Fig. 9). In general, the MPI-ESM model underestimated the SIE (by about $14 \%$ for CMIP5) and SIV (18\%). The Modini forcing reduces this offset for the SIE to about $9 \%$ on average, and performed best during the winter season. In contrast, the offset of the SIV seasonal cycle increases slightly to about $25 \%$.

The observed decrease in SIE is about $-5.1 \times$ $10^{4} \mathrm{~km}^{2} \mathrm{yr}^{-1}$ in March and even about $-9.7 \times 10^{4} \mathrm{~km}^{2} \mathrm{yr}^{-1}$ in September (Fig. 10). The original CMIP5-experiments and Modini-NCEP can only capture half of this SIE downward trend and the SIE of Modini-ERAI shows no trend at all during the modelled period.

However, both Modini-MPI-ESM experiments show a very large (about $60 \%$ ) and significant correlation of the de- 

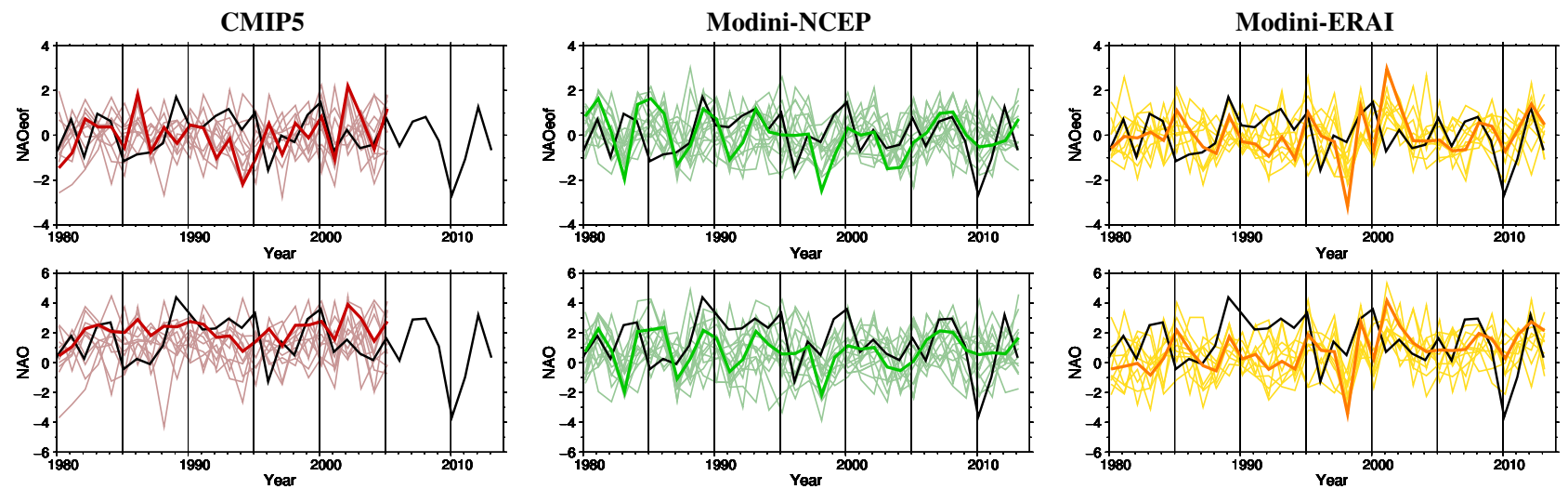

Figure 8. Winter-NAO index estimated according to the definition of Hurrell et al. (2003) (top) and Li and Wang (2003) (bottom). Thin coloured lines indicate individual ensemble members, thick coloured lines indicate the NAO calculated from the ensemble mean sea surface pressure. Black lines indicate the reference NAO calculated from ERA-interim surface pressure.

Table 4. SIE and SIV correlation coefficients from 1982 onwards for Modini-NCEP and Modini-ERAI, based on detrended March and September values. The significance is estimated for a $95 \%$ confidence level, serial correlation does not play a role here.

\begin{tabular}{ccccccc}
\hline & \multicolumn{2}{c}{ Modini-NCEP } & & \multicolumn{2}{c}{ Modini-ERAI } \\
\cline { 3 - 4 } \cline { 7 - 7 } & & CC & Sign. & & CC & Sign. \\
\hline SIE & 3 & 0.62 & high & & 0.62 & high \\
SIE & 9 & 0.58 & high & & 0.62 & weak \\
SIV & 3 & 0.49 & weak & & 0.15 & weak \\
SIV & 9 & 0.42 & high & & 0.16 & weak \\
\hline
\end{tabular}

trended SIE time series in March and September (Table 4). Despite the anthropogenic forcing, the observed decrease in SIV cannot be reproduced with MPI-ESM or Modini-MPIESM (Fig. 11); however, the detrended time series still have a significant correlation for the SIV, in particular for ModiniNCEP (Table 4).

\section{Conclusions}

We extended the fully coupled climate Max Planck Institute Earth System Model (MPI-ESM) by assimilating surface wind anomalies to force the oceanic component (MPIOM). This is an easy-to-implement method, because ocean models already provide options for external wind forcing. The resulting model is named Modini-MPI-ESM. In contrast to a full three-dimensional ocean initialization with temperature and salinity (e.g. Matei et al., 2012), this method interferes with the ESM only through the two-dimensional wind stress anomalies at the ocean's and sea ice's surface, while all other feedbacks exist as in the fully coupled MPI-ESM. We are able to reproduce parts of the climate variability of several major modes (e.g. ENSO, NAO, SAM) as well as the response of the SST, SAT, and SIE. Even the meridional overturning in the Atlantic (AMOC) comes close to observed strength and variations. However, with respect to the AMV variability, Modini-MPI-ESM shows only marginal improvement compared to MPI-ESM. This method is a superior approach for ocean and sea ice reconstruction over the period when good wind stress data are available. We avoid corrupting important feedbacks associated with heat and radiative exchange between the ocean and the atmosphere. We also avoid the too strong sensitivity of the ocean circulation in models run under mixed boundary conditions (for further discussion of this issue see Griffies et al., 2009). Running the coupled model this way for a number of decades is also a possible way to initialise climate models for long-term predictions, which has been demonstrated by Ding et al. (2013) with the coarser resolved Kiel Climate Model (KCM).

In general, Modini-MPI-ESM performs better (with respect to the selected climate indicators) with the NCEPcsfr wind forcing than the ERAI wind forcing. Both reanalysis products aim to represent the observed historical climate as well as possible and, therefore, they assimilate a huge amount of observational data. However, the wind speed over the open ocean is relatively weakly constrained in these products as less observations are available in this area compared to temperature records over land for example. Therefore these reanalysis products can differ depending on the region and time frame and might have different strengths and drawbacks. This effect might also increase for higher resolved ESMs. Ding et al. (2014b) already demonstrated with their partially coupled KCM that differences in the wind stress products NCEP and ECMWF-40 Year Reanalysis (ERA40) reanalysis wind-field anomalies (the predecessors of NCEPcsfr and ERAI) result in two groups of ensemble members separating in the 1960s and again in the 2000s (see their Fig. 2b).

Although the performance of almost all ESMs is quite poor with respect to the surface temperatures in the up- 

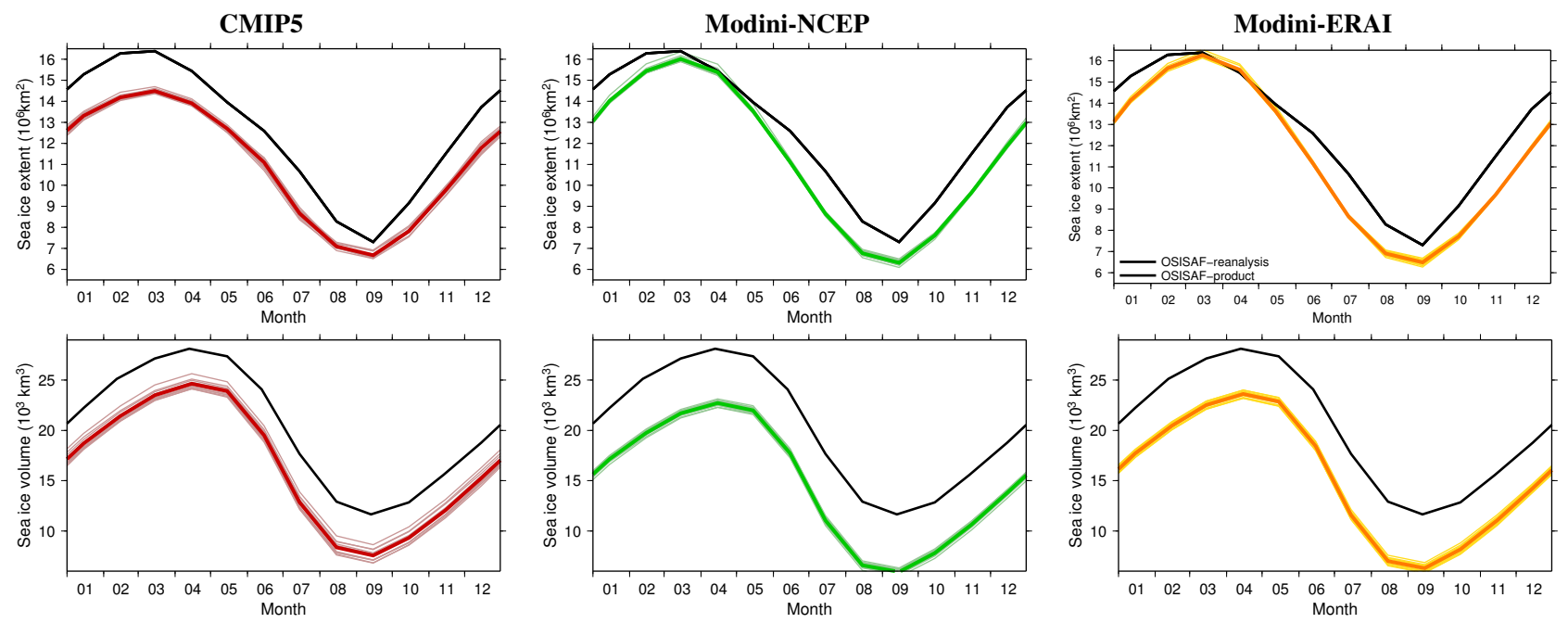

Figure 9. Mean seasonal cycle of sea ice extent (top) and sea ice volume (bottom) for CMIP5-MPI-ESM (red, 10 ensemble members), Modini-NCEP (green, 15 ensemble members), and Modini-ERAI (orange, 10 ensemble members). Black lines indicate references according to OSISAF (Andersen et al., 2012) and PIOMAS (Zhang and Rothrock, 2003; Schweiger et al., 2011) for SIE and SIV, respectively.
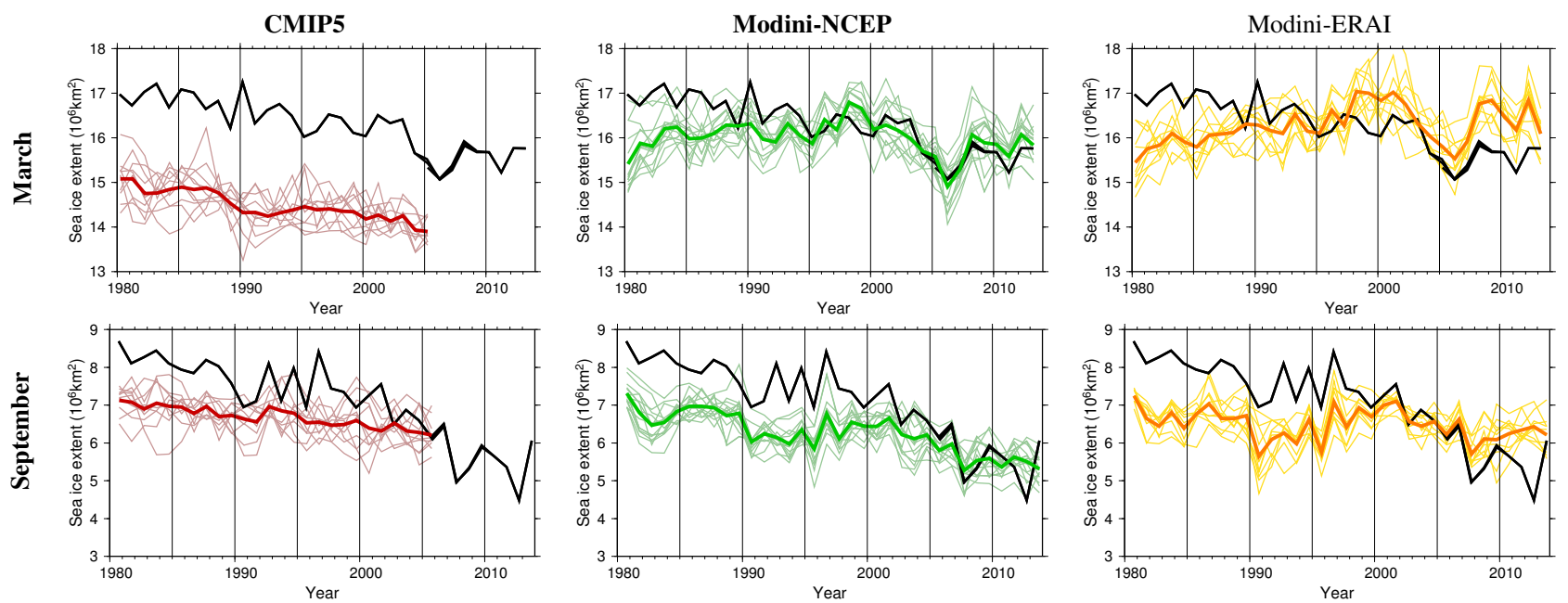

Figure 10. Monthly means of Arctic sea ice extent (concentration $\geq 15 \%$ ) for March (top) and September (bottom) for the CMIP5-MPIESM (10 ensembles members), Modini-NCEP (15), and Modini-ERAI (10). Light colours indicate individual ensemble members. Black line shows OSISAF data (reprocessed until 2009 and operational since 2008) as reference.

welling regions and particularly in the Atlantic (compare Fig. 1a), Modini-MPI-ESM shows skills at reproducing variations in the AMOC, the NAO, and the time series of the Arctic SIE. The very high and significant correlation of the AMOC since the availability of observations in 2005, leads to the speculation that the 5-year oscillation modelled between 1985 and 2005 is not only a model result, but could have been observed, too. Whether or not this skill can be transferred to hindcast historical fluctuations of these parameters will be subject to upcoming experiments.

We confined our analysis to an anomaly forcing. However, additional model experiments (not shown here) indicate that using the total wind stress, rather than wind stress anomalies, to drive Modini-MPI-ESM produces quite similar results. But keeping in mind that Modini-MPI-ESM can be used as a tool for initialising a coupled model for making decadal forecasts we favour the anomaly forcing, which reduces model drifts due to different mean climate states. However, a model drift cannot be eliminated completely as the wind-stress overwriting interferes somewhat with the physical consistency in the coupled model processes and because of the applied 6-hourly wind forcing, which results in a stronger surface mixing and hence in deeper mixed ocean surface layers at midlatitudes. This is quite obvious in our analysis of the PDO and (to a lesser extent) in the AMV which all show a spin-up phase of a few years. This result is 

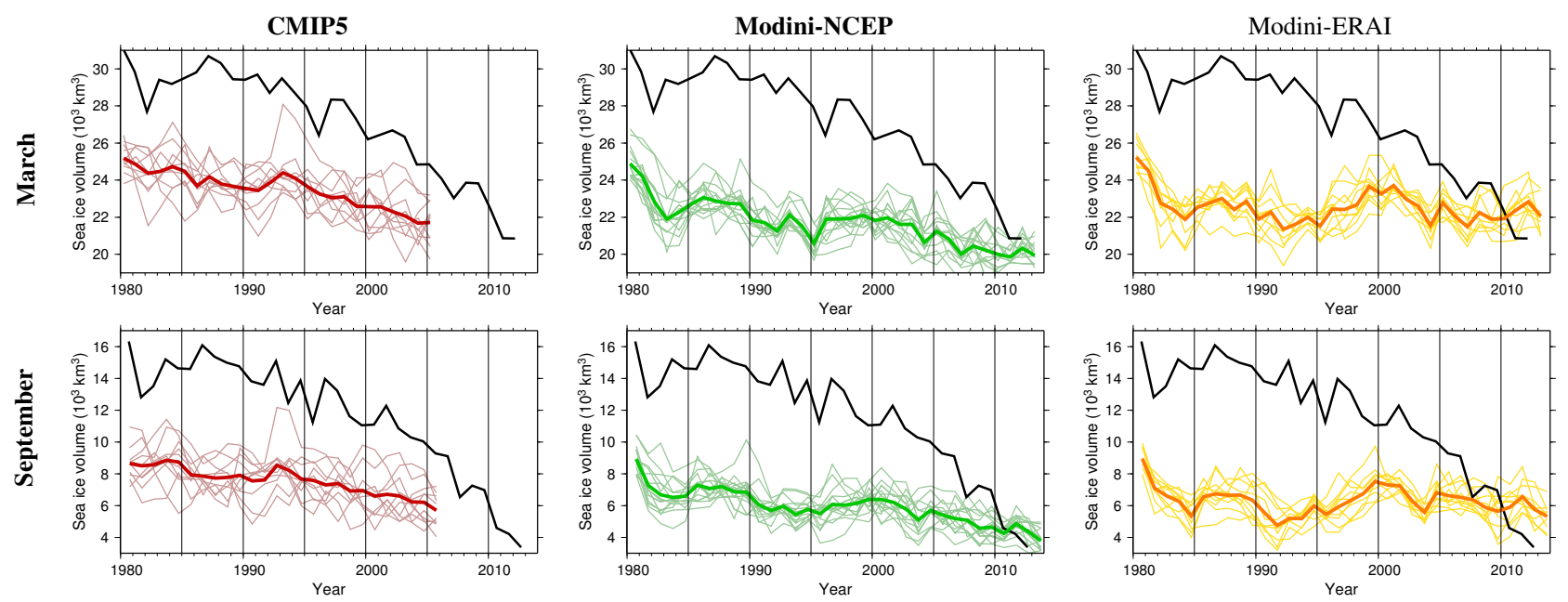

Figure 11. Like Fig. 10, but for Arctic sea ice volume. Black line shows PIOMAS data as reference.

consistent with Lu and Zhao (2012), who also observed a climate bias with a similar partial coupling approach, although their problems with drift arose mostly when they used the observed wind in the bulk formulae to compute fluxes of heat and moisture, something we do not do here.

The Modini initialisation provides an easy and straightforward method to initialise a coupled ESM by bringing the model close to the observed state and trajectory, at least in some sectors, notably in the Pacific. This essential forecast prerequisite is achieved without any additional data assimilation like the much more complex and sophisticated twostep forecast procedure presented in Kröger et al. (2012) and Matei et al. (2012) for the MPI-ESM, based on initialisations with oceanic synthesis fields (Pohlmann et al., 2009). Using the KCM, Ding et al. (2013) already demonstrated that the Modini approach has a potential forecast skill for climate shifts in the Pacific. The initialisation of the climate system in Modini-MPI-ESM could, perhaps, be improved further if the surface heat and freshwater fluxes were adjusted using observed time series, e.g. using a nudging technique as described in Servonnat et al. (2014), a topic for future research. We will investigate the performance of Modini-MPI-ESM as an initialisation technique for decadal hindcasts (historical forecasts) in upcoming experiments. 


\section{Appendix A}

aC)

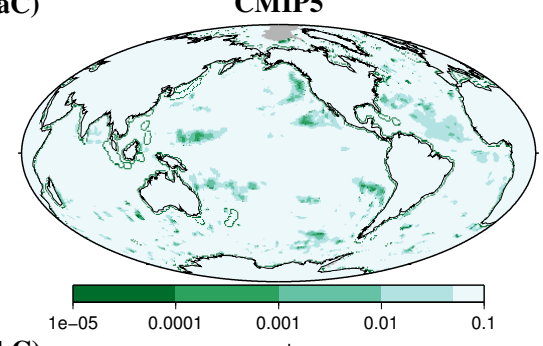

bC)

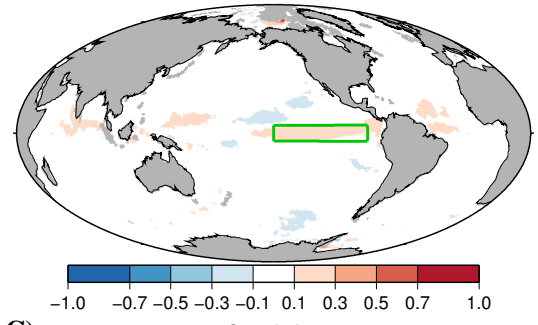

aC)

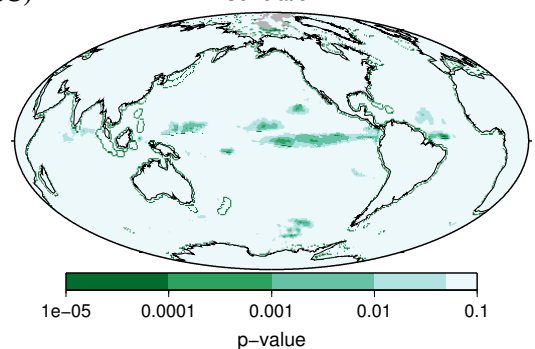

aN)

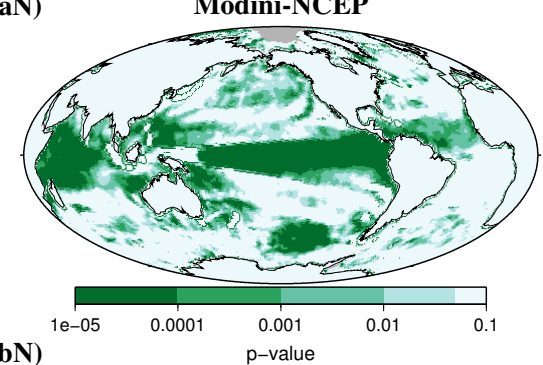

bN)

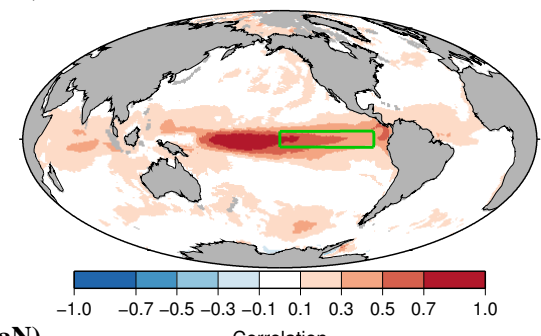

aN)

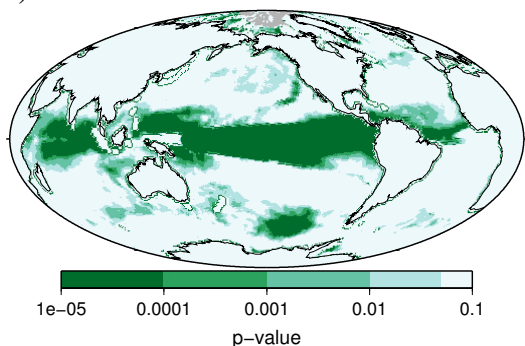

aE)

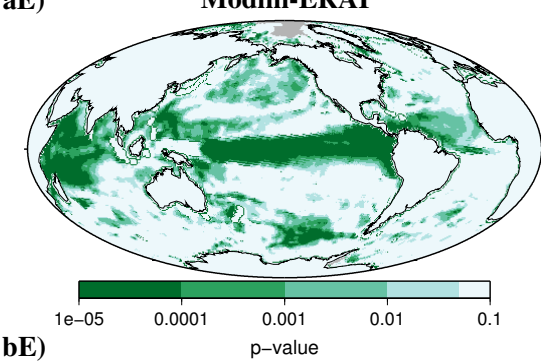

b)
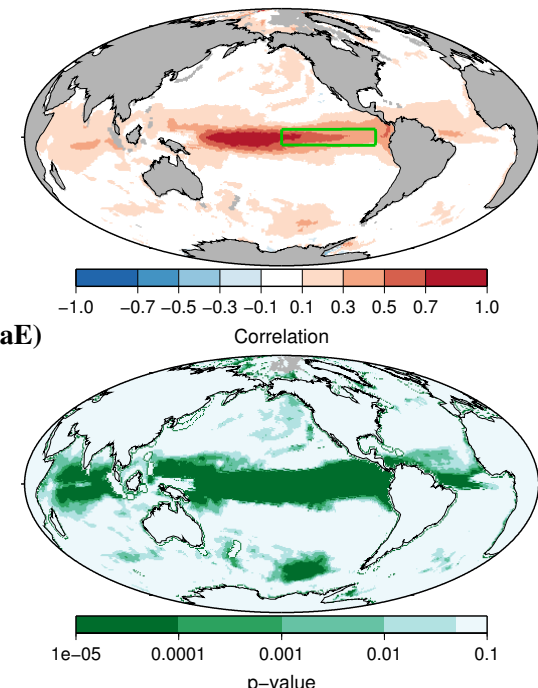

Figure A1. (a) Significance ( $p$ value) for the annual mean correlation between model and the reference SST, according to Fig. 1. (b) Correlation between the model and the reference SST like in Fig. 1, but for monthly means. (c) Corresponding significance for monthly mean correlations shown in (b). 
Table A1. Abbreviations.

\begin{tabular}{|c|c|}
\hline AAO & Antarctic Oscillation \\
\hline AMO & Atlantic Multidecadal Oscillation \\
\hline AMOC & Atlantic Meridional Overturning Circulation \\
\hline AMV & Atlantic Multidecadal Variability \\
\hline CMIP5 & Coupled Model Intercomparison Project Phase 5 \\
\hline ECHAM & Acronym from ECMWF and Hamburg \\
\hline ENSO & El Niño-Southern Oscillation \\
\hline EOF & Empirical orthogonal function \\
\hline ERA40 & ECMWF-40 Year Reanalysis \\
\hline ERAI & ERA-Interim reanalysis \\
\hline ESM & Earth system model \\
\hline GHG & Greenhouse Gas \\
\hline GPHA & Geopotential height anomaly \\
\hline HADIsst & Met Office Hadley Centre's sea ice and sea surface temperature data set \\
\hline $\mathrm{KCM}$ & Kiel Climate Model \\
\hline IPCC & Intergovernmental Panel on Climate Change \\
\hline LR & Low resolution \\
\hline MOCHA & Meridional Overturning Circulation and Heatflux Array \\
\hline Modini & Model initialisation by partially coupled spin-up \\
\hline MPI & Max Planck Institute \\
\hline MPI-ESM & Max Planck Institute Earth System Model \\
\hline MPIOM & Max Planck Institute Ocean Model \\
\hline NAO & North Atlantic Oscillation \\
\hline NCEP & National Centers for Atmospheric Prediction \\
\hline NCEPcsfr & National Centers for Environmental Prediction, Climate Forecast System Reanalysis \\
\hline NSIDC-CDR & National Snow and Ice Data Center-Climate Data Record \\
\hline OSISAF & Ocean and Sea Ice Satellite Application Facility \\
\hline $\mathrm{PC}$ & Principal component \\
\hline PDO & Pacific Decadal Oscillation \\
\hline PIOMAS & Pan-Arctic Ice-Ocean Modeling and Assimilation System Data Sets - (from the retrospective investigation) \\
\hline RAPID & Rapid Climate Change programme \\
\hline $\mathrm{RCP}$ & Representative concentration pathway \\
\hline SAM & Southern Annular Mode \\
\hline SAT & Surface air temperature \\
\hline SST & Sea surface temperature \\
\hline SSS & Sea surface salinity \\
\hline SLP & Sea level pressure \\
\hline SIE & Sea ice extent \\
\hline SIV & Sea ice volume \\
\hline LR & Atmospheric resolution: T63L47, default; ocean-sea ice resolution GR15L40, default $\approx 1.5^{\circ}$ \\
\hline
\end{tabular}


Acknowledgements. This work was funded by the BMBF grant 01LP1134A, which is gratefully acknowledged. We thank all the people of the Max Planck Institute for Meteorology (MPI) and the German Climate Computing Center (DKRZ) who worked on the development of MPI-ESM used in the CMIP5 experiments. The simulations have been performed at the German High Performance Computing Centre for Climate and Earth System Research (DKRZ) and the AWI. The authors wish to thank Helge Gößling, Klaus Grosfeld, Helmut Haak, and all members of the sea ice group at AWI for their support and fruitful discussions, and two anonymous reviewers for their helpful suggestions which improved the manuscript.

Edited by: W. Hazeleger

\section{References}

Andersen, S., Breivik, L.-A., Eastwood, S., Øystein Godøy, Lavergne, T., Lind, M., Porcires, M., Schyberg, H., and Tonboe, R.: Ocean \& Sea Ice SAF Sea Ice Product Manual, version 3.8, 2012.

Cunningham, S. A., Kanzow, T., Rayner, D., Baringer, M. O., Johns, W. E., Marotzke, J., Longworth, H. R., Grant, E. M., Hirschi, J. J.-M., Beal, L. M., Meinen, C. S., and Bryden, H. L.: Temporal Variability of the Atlantic Meridional Overturning Circulation at $26.5^{\circ} \mathrm{N}$, Science, 317, 935-938, doi:10.1126/science.1141304, 2007.

Dee, D. P., Uppala, S. M., Simmons, A. J., Berrisford, P., Poli, P., Kobayashi, S., Andrae, U., Balmaseda, M. A., Balsamo, G., Bauer, P., Bechtold, P., Beljaars, A. C. M., van de Berg, L., Bidlot, J., Bormann, N., Delsol, C., Dragani, R., Fuentes, M., Geer, A. J., Haimberger, L., Healy, S. B., Hersbach, H., Hólm, E. V., Isaksen, L., Kållberg, P., Köhler, M., Matricardi, M., McNally, A. P., Monge-Sanz, B. M., Morcrette, J.-J., Park, B.-K., Peubey, C., de Rosnay, P., Tavolato, C., Thépaut, J.-N., and Vitart, F.: The ERA-Interim reanalysis: configuration and performance of the data assimilation system, Q. J. Roy. Meteor. Soc., 137, 553-597, doi:10.1002/qj.828, 2011.

Deser, C. and Wallace, J.: Large scale atmospheric circulation features of warm and cold episodes in the tropical Pacific, J. Climate, 3, 1254-1281, doi:10.1175/15200442(1990)003<1254:LSACFO>2.0.CO;2, 1990.

Ding, H., Greatbatch, R. J., Latif, M., Park, W., and Gerdes, R.: Hindcast of the $1976 / 77$ and $1998 / 99$ climate shifts in the Pacific, J. Climate, 26, 7650-7661, doi:10.1175/JCLI-D-12$00626.1,2013$.

Ding, H., Greatbatch, R. J., and Gollan, G.: Tropical impact on the interannual variability and long-term trend of the Southern Annular Mode during austral summer from 1960/1961 to 2001/2002, Clim. Dynam., 1-14, doi:10.1007/s00382-014-2299$\mathrm{x}, 2014 \mathrm{a}$.

Ding, H., Greatbatch, R. J., Park, W., Latif, M., Semenov, V. A., and Sun, X.: The variability of the East Asian summer monsoon and its relationship to ENSO in a partially coupled climate model, Clim. Dynam., 42, 367-379, doi:10.1007/s00382012-1642-3, 2014b.
Ding, Q., Steig, E. J., Battisti, D. S., and Wallace, J. M.: Influence of the tropics on the Southern Annular Mode, J. Climate, 25, 63306348, doi:10.1175/JCLI-D-11-00523.1, 2012.

Eden, C. and Jung, T.: North Atlantic interdecadal variability: Oceanic response to the North Atlantic Oscillation (1865-1997), J. Climate, 14, 676-691, doi:10.1175/15200442(2001)014<0676:NAIVOR>2.0.CO;2, 2001.

Eden, C. and Willebrand, J.: Mechanism of interannual to decadal variability of the North Atlantic Circulation, J. Climate, 14, 2266-2280, doi:10.1175/15200442(2001)014<2266:MOITDV>2.0.CO;2, 2001.

Enfield, D. B., Mestas-Nuñez, A. M., and Trimble, P. J.: The Atlantic Multidecadal Oscillation and its relation to rainfall and river flows in the continental U.S., Geophys. Res. Lett., 28, 2077-2080, doi:10.1029/2000GL012745, 2001.

Fan, M. and Schneider, E. K.: Observed decadal North Atlantic tripole SST variability. Part I: Weather noise forcing and coupled response, J. Atmos. Sci., 69, 35-50, doi:10.1175/JAS-D-11018.1, 2011.

Giorgetta, M. A., Jungclaus, J., Reick, C. H., Legutke, S., Bader, J., Böttinger, M., Brovkin, V., Crueger, T., Esch, M., Fieg, K., Glushak, K., Gayler, V., Haak, H., Hollweg, H.-D., Ilyina, T., Kinne, S., Kornblueh, L., Matei, D., Mauritsen, T., Mikolajewicz, U., Mueller, W., Notz, D., Pithan, F., Raddatz, T., Rast, S., Redler, R., Roeckner, E., Schmidt, H., Schnur, R., Segschneider, J., Six, K. D., Stockhause, M., Timmreck, C., Wegner, J., Widmann, H., Wieners, K.-H., Claussen, M., Marotzke, J., and Stevens, B.: Climate and carbon cycle changes from 1850 to 2100 in MPI-ESM simulations for the Coupled Model Intercomparison Project phase 5, J. Advances in Modeling Earth Systems, 5, 572-597, doi:10.1002/jame.20038, 2013.

Gong, D. and Wang, S.: Definition of Antarctic Oscillation index, Geophys. Res. Lett., 26, 459-462, doi:10.1029/1999GL900003, 1999.

Greatbatch, R. J., Gollan, G., Jung, T., and Kunz, T.: Factors influencing Northern Hemisphere winter mean atmospheric circulation anomalies during the period 1960/61 to 2001/02, Q. J. Roy. Meteor. Soc., 138, 1970-1982, doi:10.1002/qj.1947, 2012.

Griffies, S. M., Biastoch, A., Böning, C., Bryan, F., Danabasoglu, G., Chassignet, E. P., England, M. H., Gerdes, R., Haak, H., Hallberg, R. W., Hazeleger, W., Jungclaus, J., Large, W. G., Madec, G., Pirani, A., Samuels, B. L., Scheinert, M., Gupta, A. S., Severijns, C. A., Simmons, H. L., Treguier, A. M., Winton, M., Yeager, S., and Yin, J.: Coordinated Ocean-ice Reference Experiments (COREs), Ocean Model., 26, 1-46, doi:10.1016/j.ocemod.2008.08.007, 2009.

Hibler, W. D.: A dynamic thermodynamic sea ice model, J. Phys. Oceanogr., 9, 815-846, doi:10.1175/15200485(1979)009<0815:ADTSIM>2.0.CO;2, 1979.

Hurrell, J. W., Kushnir, Y., Ottersen, G., and Visbeck, M.: An overview of the North Atlantic Oscillation, in: The North Atlantic Oscillation: Climatic Significance and Environmental Impact, edited by: Hurrell, J. W., Kushnir, Y., Ottersen, G., and Visbeck, M., 1-35, American Geophysical Union, doi:10.1029/134GM01, 2003.

Jochum, M., Briegleb, B. P., Danabasoglu, G., Large, W. G., Norton, N. J., Jayne, S. R., Alford, M. H., and Bryan, F. O.: The impact of oceanic near-inertial waves on climate, J. Climate, 26, 28332844, doi:10.1175/JCLI-D-12-00181.1, 2012. 
Jungclaus, J. H., Fischer, N., Haak, H., Lohmann, K., Marotzke, J., Matei, D., Mikolajewicz, U., Notz, D., and von Storch, J. S.: Characteristics of the ocean simulations in the Max Planck Institute Ocean Model (MPIOM) the ocean component of the MPIEarth system model, J. Advances in Modeling Earth Systems, 5, 422-446, doi:10.1002/jame.20023, 2013.

Kaplan, A., Cane, M. A., Kushnir, Y., Clement, A. C., Blumenthal, M. B., and Rajagopalan, B.: Analyses of global sea surface temperature 1856-1991, J. Geophys. Res., 103, 18567-18589, doi:10.1029/97JC01736, 1998.

Kirtman, B. P. and Shukla, J.: Interactive coupled ensemble: A new coupling strategy for CGCMs, Geophys. Res. Lett., 29, 5.1-5.4, doi:10.1029/2002GL014834, 2002.

Kosaka, Y. and Xie, S.-P.: Recent global-warming hiatus tied to equatorial Pacific surface cooling, Nature, 501, 403-407, letter, 2013.

Kröger, J., Müller, W. A., and von Storch, J.-S.: Impact of different ocean reanalyses on decadal climate prediction, Clim. Dynam., 39, 795-810, doi:10.1007/s00382-012-1310-7, 2012.

Large, W. G. and Yeager, S. G.: The global climatology of an interannually varying air-sea flux data set, Clim. Dynam., 33, 341364, doi:10.1007/s00382-008-0441-3, 2009.

Li, J. and Wang, J. X. L.: A New North Atlantic Oscillation Index and Its Variability, Adv. Atmos. Sci., 20, 661-676, doi:10.1007/BF02915394, 2003.

Lu, J. and Zhao, B.: The role of oceanic feedback in the climate response to doubling $\mathrm{CO}_{2}$, J. Climate, 25, 7544-7563, doi:10.1175/JCLI-D-11-00712.1, 2012.

Mantua, N. J., Hare, S. R., Zhang, Y., Wallace, J. M., and Francis, R. C.: A Pacific Interdecadal Climate Oscillation with Impacts on Salmon Production, B. Am. Meteorol. Soc., 78, 1069-1079, doi:10.1175/1520-0477(1997)078<1069:APICOW>2.0.CO;2, 1997.

Marshall, G. J.: Trends in the Southern Annular Mode from Observations and Reanalyses, J. Climate, 16, 4134-4143, doi:10.1175/1520-0442(2003)016<4134:TITSAM>2.0.CO;2, 2003.

Matei, D., Pohlmann, H., Jungclaus, J., Müller, W., Haak, H., and Marotzke, J.: Two Tales of Initializing Decadal Climate Prediction Experiments with the ECHAM5/MPI-OM Model, J. Climate, 25, 8502-8523, doi:10.1175/JCLI-D-11-00633.1, 2012.

McCormick, M. P., Thomason, L. W., and Trepte, C. R.: Atmospheric effects of the Mt Pinatubo eruption, Nature, 373, 399404, doi:10.1038/373399a0, 1995.

Meehl, G. A., Stocker, T. F., Collins, W. D., Friedlingstein, P., Gaye, A. T., Gregory, J. M., Kitoh, A., Knutti, R., Murphy, J. M., Noda, A., Raper, S. C. B., Watterson, I. G., Weaver, A. J., and Zhao, Z.-C.: Global Climate Projections, in: Climate Change 2007: The Physical Science Basis. Contribution of Working Group I to the Fourth Assessment Report of the Intergovernmental Panel on Climate Change, edited by: Solomon, S., Qin, D., Manning, M., Chen, Z., Marquis, M., Averyt, K. B., Tignor, M., and Miller, H. L., 749-845, Cambridge University Press, Cambridge, United Kingdom and New York, NY, USA, 2007.

Mo, K. C.: Relationships between low-frequency variability in the Southern Hemisphere and Sea Surface Temperature Anomalies, J. Climate, 13, 3599-3610, doi:10.1175/15200442(2000)013<3599:RBLFVI>2.0.CO;2, 2000.
Murphy, J., Kattsov, V., Keenlyside, N., Kimoto, M., Meehl, G., Mehta, V., Pohlmann, H., Scaife, A., and Smith, D. Towards Prediction of Decadal Climate Variability and Change, Procedia Environmental Sciences, 1, 287-304, doi:10.1016/j.proenv.2010.09.018, 2010.

Müller, W. A., Baehr, J., Haak, H., Jungclaus, J. H., Kröger, J., Matei, D., Notz, D., Pohlmann, H., von Storch, J. S., and Marotzke, J.: Forecast skill of multi-year seasonal means in the decadal prediction system of the Max Planck Institute for Meteorology, Geophys. Res. Lett., 39, 1-7, doi:10.1029/2012GL053326, 2012.

Notz, D., Haumann, F. A., Haak, H., Jungclaus, J. H., and Marotzke, J.: Arctic sea-ice evolution as modeled by Max Planck Institute for Meteorology's Earth system model, J. Advances in Modeling Earth Systems, 5, 173-194, doi:10.1002/jame.20016, 2013.

Philander, S. G. (Ed.): El Niño, La Niña, and the Southern Oscillation, Vol. 46, Academic Press, 1990.

Pohlmann, H., Jungclaus, J. H., Köhl, A., Stammer, D., and Marotzke, J.: Initializing decadal climate predictions with the GECCO oceanic synthesis: Effects on the North Atlantic, J. Climate, 22, 3926-3938, doi:10.1175/2009JCLI2535.1, 2009.

Rayner, N. A., Parker, D. E., Horton, E. B., Folland, C. K., Alexander, L. V., Rowell, D. P., Kent, E. C., and Kaplan, A.: Global analyses of sea surface temperature, sea ice, and night marine air temperature since the late nineteenth century, J. Geophys. Res., 108, 1-37, doi:10.1029/2002JD002670, 2003.

Riemann-Campe, K. and Gerdes, R.: Future Arctic sea ice extent: less in summer but more in winter, EGU Spring Meeting Abstracts, p. 1, 2013.

Rott, H., Skvarca, P., and Nagler, T.: Rapid collapse of Northern Larsen Ice Shelf, Antarctica, Science, 271, 788-792, doi:10.1126/science.271.5250.788, 1996.

Saha, S., Moorthi, S., Pan, H.-L., Wu, X., Wang, J., Nadiga, S., Tripp, P., Kistler, R., Woollen, J., Behringer, D., Liu, H., Stokes, D., Grumbine, R., Gayno, G., Wang, J., Hou, Y.-T., Chuang, H.Y., Juang, H.-M. H., Sela, J., Iredell, M., Treadon, R., Kleist, D., Van Delst, P., Keyser, D., Derber, J., Ek, M., Meng, J., Wei, H., Yang, R., Lord, S., Van Den Dool, H., Kumar, A., Wang, W., Long, C., Chelliah, M., Xue, Y., Huang, B., Schemm, J.-K., Ebisuzaki, W., Lin, R., Xie, P., Chen, M., Zhou, S., Higgins, W., Zou, C.-Z., Liu, Q., Chen, Y., Han, Y., Cucurull, L., Reynolds, R. W., Rutledge, G., and Goldberg, M.: The NCEP Climate Forecast System Reanalysis, B. Am. Meteorol. Soc., 91, 1015-1057, doi:10.1175/2010BAMS3001.1, 2010.

Schweiger, A., Lindsay, R., Zhang, J., Steele, M., Stern, H., and Kwok, R.: Uncertainty in modeled Arctic sea ice volume, J. Geophys. Res., 116, 1-21, doi:10.1029/2011JC007084, 2011.

Semtner, A. J. J.: A model for the thermodynamic groth of sea ice in numerical investigations of climate, J. Phys. Oceanogr., 6, 379-389, doi:10.1175/15200485(1976)006<0379:AMFTTG>2.0.CO;2, 1976.

Semtner, A. J. J.: Modeling the ocean in climate studies, Ann. Glaciol., 5, 133-140, 1984.

Send, U., Lankhorst, M., and Kanzow, T.: Observation of decadal change in the Atlantic meridional overturning circulation using 10 years of continuous transport data, Geophys. Res. Lett., 38, 1-5, doi:10.1029/2011GL049801, 2011.

Servonnat, J., Mignot, J., Guilyardi, E., Swingedouw, D., Séférian, R., and Labetoulle, S.: Reconstructing the subsurface ocean 
decadal variability using surface nudging in a perfect model framework, Clim. Dynam., 44, 315-338, doi:10.1007/s00382014-2184-7, 2014.

Shepherd, A., Wingham, D., Payne, T., and Skvarca, P.: Larsen Ice Shelf has progressively thinned, Science, 302, 856-859, doi:10.1126/science.1089768, 2003.

Smeed, D. A., McCarthy, G. D., Cunningham, S. A., FrajkaWilliams, E., Rayner, D., Johns, W. E., Meinen, C. S., Baringer, M. O., Moat, B. I., Duchez, A., and Bryden, H. L.: Observed decline of the Atlantic meridional overturning circulation 20042012, Ocean Sci., 10, 29-38, doi:10.5194/os-10-29-2014, 2014.

Stocker, T. F., Qin, D., Plattner, G.-K., Tignor, M., Allen, S. K., Boschung, J., Nauels, A., Xia, Y., Bex, V., and Midgley, P. M. (Eds.): Climate Change 2013: The Physical Science Basis. Contribution of Working Group I to the Fifth Assessment Report of the Intergovernmental Panel on Climate Change, Cambridge University Press, Cambridge, United Kingdom and New York, NY, USA, 2013.

Thompson, D. W. J. and Wallace, J. M.: Annular Modes in the Extratropical Circulation. Part I: Month-to-Month Variability*, J. Climate, 13, 1000-1016, doi:10.1175/15200442(2000)013<1000:AMITEC>2.0.CO;2, 2000.
Trenberth, K. E.: The Definition of El Niño, B. Am. Meteorol. Soc., 78, 2771-2777, doi:10.1175/15200477(1997)078<1069:APICOW>2.0.CO;2, 1997.

Vuille, M. and Garreaud, R. D.: Ocean-Atmosphere Interactions on Interannual to Decadal Time Scales, in: The SAGE Handbook of Environmental Change: Volume 1, edited by: Matthews, J. A., 471-497, SAGE Publications Ltd., doi:10.4135/9781446253045, 2012.

Weisse, R., Mikolajewicz, U., and Maier-Reimer, E.: Decadal variability of the North Atlantic in an ocean general circulation model, J. Geophys. Res., 89, 12411-12421, 1994.

Zhang, J. and Rothrock, D. A.: Modeling Global Sea Ice with a Thickness and Enthalpy Distribution Model in Generalized Curvilinear Coordinates, Mon. Weather Rev., 131, 845-861, doi:10.1175/1520-0493(2003)131<0845:MGSIWA>2.0.CO;2, 2003. 